\title{
Study of Immersion on Narrative Video Mapping Case Study: NRMO Lzy Visual in Jogjakarta Video Mapping Festival 2018
}

\author{
(New Media and Technology for the Arts) \\ Andri Pahrulroji*, Intan Rizky Mutiaz, Banung Grahita \\ Institut Teknologi Bandung \\ Bandung, Indonesia \\ *pahrulroji.a@gmail.com, intannrm@itb.ac.id, banung@itb.ac.id
}

\begin{abstract}
The term "immersion" is often found in several researches regarding to virtual reality and interactive media, but have yet to be discovered whether immersion can be created in a video mapping performance. According to Nillson, Nordahl and Seraafin's taxonomy, immersion is divided into three categories, in which each of them represents the dimension of immersion as a system, narrative, and challenge based immersion. A case study on NRMO Lzy Visual Jogjakarta Video Mapping Festival 2018, one of the best shows performed on the first video mapping festival in Indonesia that includes narration. Therefore, this study is aimed to find whether this video mapping system and narration can create an immersion and how the immersion is built. The study was conducted through descriptive qualitative method and pre experiment design. The researcher would first analyze the NRMO video mapping structure with extracting theories from the other knowledge to facilitate research, then recreated the performance to be showed to audiences. An interview was held with the audiences and analyzed according to variable on taxonomy. The results find that narrative video mapping can create a narrative immersion and system immersion. There are several aspects that produce these immersions, including the narration presentation which includes story of life and the video mapping technology that performed extraordinary audiovisual experience in a large size medium. This research will certainly be reference for research related to video mapping, as well as for video mapping creators who want to create immersion on video mapping.
\end{abstract}

Keywords-video mapping, projection mapping, immersion, system immersion, narrative immersion, challenge-based immersion

\section{INTRODUCTION}

The term video mapping or projection mapping in Indonesia has been familiar for now. Since 2010, research, development, and creation of video mapping have been carried out everywhere, including techniques for mapping picture or video on objects that produce anomorphism (optical illusion on objects). Video mapping is one of the newest video projection techniques used to turn almost any surfaces into a dynamic video display [1]. According to Maniello "Video mapping (also called 3D mapping, projection mapping, or simply mapping) is a particular form of Augmented Reallty $(A R)$, or reality created by the developer, a king of development of the dicipline characterized by greater completeness and consistency" [2]. Video mapping is also one of the media which can be capable to convey a message like the other media can consist of sound, images, text, animation, and digital manipulation video, according to Vaughan, while referring to Hotstetter in Vaughan [3], moreover, if being packeged with conceptual design to become narrative video mapping. Video mapping like like a film which is an audio-visual communication medium in which there are narrative or non-narrative elements, visual elements, and sound elements [4]. However, the story of video mapping assisted by projection technology on an object is still questionable whether it can produce immersion or not.

Immersion research is usually connected with the study of virtual reality and interactive media like on video game, but of course video mapping has a difference from that. Video games makes mental absorption experience when facing challenges that match one's capabilities, including the challenges when exposed to nonparticipatory media. Users will have desire in it and want to try again (challenge-based immersion). Video mapping has a powerful component to produce immersion which can make the audience to be in an intense and focus awareness condition on the performed story and event, while accepting the story as real (narrative immersion). The video mapping technology can drown the audience to a multi-sensor virtual world through big screen and loud sound (immersion system), according to Nillson, Nordahl and Seraafin [5]. The fact is that statement remains a speculation. Therfore, we will look for validty with this research.

Video mapping which is made into narrative performances such as case studies in research, Video Mapping NRMO Lzy Visual in Jogjakarta Video Mapping Festival 2018 (JVMF 2018), has a story to be conveyed to the audience. NRMO is 
the title of the video work created by Lzy Visual from Surabaya and performed on first video mapping festival in Yogyakarta, Indonesia, in 2018. JVMF displayed various works from video mapping creators in Indonesia. NRMO is a Javanese language which means accepting. It exposed a story of human life experienced by everyone, telling us to keep trying and struggling to face various kinds of life problems with gracefully accepting it so we don't forget to rest and introspect ourselves before taking the next decision. This video mapping work is an interesting one compared to the others because not all video mapping projects bring a message like that as video mapping, sometimes, only displays visual presentations without the accompanying story.

This research aims at proving whether video mapping is capable of producing any kinds of immersion in it, and how this immersion is formed, by using the taxonomy of existing conceptualizations of immersion Nillson, Nordahl and Seraafin. The immersion on video mapping will be studied using qualitative descriptive research and experiment methods with appreciators.

\section{METHODS}

This research uses descriptive qualitative research and experiment methods with video mapping case study on NRMO Lzy Visual on JVMF 2018. Research on the existence of immersion in narrative video mapping becomes the priority, but firstly, the researcher must find the elements and narrative structures in the video mapping with extracting theories from the other knowledge to facilitate research.

First, the researcher conducted a literature study on elements in multimedia, animation, film, motion graphics, video. etc. Then, the researcher summarizes what is contained within the video mapping after the narrative elements and structures in the video mapping have been found. After that, the researcher will conduct random interviews to get responses about the NRMO video mapping to find the truth of its ability to provide immersion in the appreciator and how immersion can be arise, with the possibility that immersion cannot be present. We can understand why the immersion can emerge by studying it through "A Taxonomy of Existing Conceptualizations of Immersion" in which there is a division of immersion by system, narrative, and challenges, as in Nillson, Nordahl and Seraafin [5] propose that the conceptualization of immersion is presented throughout the introduction, the subsections can be organized into threedimensional taxonomies. Definitions can be presented and can be broadly divided into three categories based on the relationship of the three, named as a system property (immersion system), subjective response to narrative immersion or subjective response to challenges (challengebased immersion).

\section{VIDEO MAPPING}

Video mapping is technique that uses lighting and projection that produces anarmophism (optical illusion on objects). Video mapping is one of the latest projection video techniques used by almost every surface to become dynamic video displays, video projection mapping [1]. This dynamic results in frequent appearance of optical illusions on video mapping objects and according to Maniello "Video mapping (also called 3D mapping, projection mapping, or simply mapping) is a particular form of Augmented Reallty (AR), or reality created by the developer, a king of development of the dicipline characterized by greater completeness and consistency" [2]. The type of video mapped in video mapping is usually an animated one. According to G. Djalle et al, it can be said that animation is a medium that was born from two conventions or disciplines, named films and pictures. To be able to understand and use animation techniques, both conventions must be understood. Another term for animation is motion graphics. It is referred to a motion picture because of the manufacturing process that uses sequential images and manipulation so that the images appear to be moving using software. Seen from its dimensions, the animation is divided into two, named two-dimensional (2D) and three-dimensional (3D) animations. The $2 \mathrm{D}$ animation uses 2 viewpoints that represent width - left-right movement and height - top-down movement. Meanwhile, three-dimensional animation uses three points of view which represent two points of view in 2D animation plus back and forth movements where the object is denser. The 3D point of view on the object will make the movement to be more real and apply the similar treatment in the video mapping show [6].

Video mapping is one of multimedia development which is a combination of two or more media. The multimedia can consist of sound, images, text, animation, and digital manipulation video, according to Vaughan, while referring to Hotstetter in Vaughan [3], multimedia is the implementation of computer in presenting and combining text, images, sound and video with an interface that allows users to do interaction with the multimedia system [3]. According to Binanto, multimedia is divided into three types: interactive, hyperactive and linear, in which video mapping os classified as linear as the audience can only enjoy the audiovisual [7]. Video mapping is one of the developments of film, while it is also often said to be a derivative of film because it has elements, structures, and production methods which are almost similar. Video mapping itself has a technical understanding in mapping video and film is one of the videos that can be arranged in the video mapping itself, in the sense that film, according to Effendy [8], is defined as the result culture and means of expression in the arts, in the development of films related to technology and the combination of artistic elements to produce quality films [9]. Apart from the video mapping film, it is also a development of animation. The type of video that refers to video mapping shows a lot of animation according to Saidi, which mentions a lot of understanding about animation. Animation, animated, and animator come from the Latin animate which means "animate". Paul Wells gave the meaning that to animate is the same as giving life to an inanimate object, therefore, Prakoso states that animate is like animating by giving motion or the impression of moving. Animation is like a film which is an 
audio-visual communication medium in which there are narrative or non-narrative elements, visual elements, and sound elements [4].

In visual narrative, video mapping is similar to narration in animation, which is a story telling through moving or still visual images and graphics. Visual narrative is a combination of a visual that can be seen, narration as a series of events, and story as a description of the sequence that connects events. Important things that are usually contained in visual narrative are: 1) the existence of the story, 2) the visual elements that are constructed to tell the story, 3) the actors or participants who play a role, 4) a visual narrative that has its own world, and 5) a visual narrative that can applied in any media [10]

Audio in video mapping is another aspect that is as important as a visual element that can build a scene to be more alive and real. Among which there are several aspects such as: 1) Dialogue, 2) Music which are useful for emphasizing an atmosphere. Music in animation is divided into two: music illustration produced from music instruments to support the scene and theme song as the film identity which is specially made based on the film narration or the popular one. Meanwhile, the sound effect is divide into three: background sound which gives impression to the special moment such as wind, water, etc.; hard effect such as volcanic eruption, gun shot, etc.; and folley - derived from the word follish - which manipulates certain sound to resemble the expected one [11]. In an animation or film, there is also an additional narrative voice called a voice over in the form of a human voice reading a story / narrative related to the video made [12].

Projection is a result of technological development that make this video mapping appears, so that it becomes an important element in it. With the projection, it is said that video mapping in displaying each surface becomes a dynamic video display. This dynamic video projection mapping results in frequent appearance of optical illusions on objects which are identical to video mapping. Optical illusions resulting from projection on the object of understanding generally occur when the observer's visual perception of an object is not the same as the object's actual attributes. That the stimuli received by the eye are then processed by our brains to convey information that is different from the actual reality. This can happen for many reasons [13]. In a video mapping show, of course the appreciator will see that the object or media that is highlighted by the projection will look different from the actual object, from various types of optical [13]. Cognitively, optical illusions can be further divided based on illusions. What happens: (1) ambiguous illusions or figure / ground, illusions that occur when more than one visual interpretation appears at the same time; (2) distorting / geometrical - optical illusions / anamorphosis, illusions that occur which distort a shape due to the placement, size, angle of the geometric elements that compose the visual; (3) paradox illusions, illusions of objects that are logically absurd or impossible but can look true; and (4) fictions, illusions that occur when we see a figure even though it doesn't actually exist.

\section{TAXONOMY OF EXISTING CONCEPTUALIZATIONS OF IMMERSION}

There are various definitions of immersion, in the book Hamlet on the Holodeck, Murray 1997 [5], "Immersion is a metaphorical term derived from the physical experience of being submerged in water. We seek the same feeling from a psychologically immersive experience that we do from a plunge in the ocean or swimming pool: the sensation of being surrounded by a completely other reality, as different as water is from air, that takes over all of our attention, our whole perceptual apparatus" In general, immersion is like being or experiencing something in it that is in the existing senses.

Nillson, Nordahl and Seraafin from summarizing the definitions of various immersion sources, immersion can be presented and can be broadly divided into three categories [5]. Based on the relationship of the three, immersion is named as a system property (system immersion), subjective responses to narrative immersion or subjective responses to challenges (challenge-based immersion). A Taxonomy of existing conceptualizations of immersion can be seen in figure 1 .

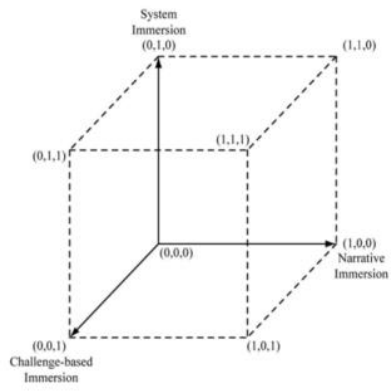

Fig. 1. A Taxonomy of existing conceptualizations of immersion [5].

\section{A. System Immersion}

System Immersion is caused by technological properties that mediate the experience. The higher the display and tracking, the higher the level of immersion will be, but also the immersion system can be in perceptual responses. Perceptual responses, mentioned as perceptual immersion, where the sensation of being surrounded by a virtual environment increases proportionally with the number of modalities provided with artificial stimulation [5] or sensory immersion mentioned by Ermi and Mäyrä which introduced that immersion refers to an audiovisual presentation that has a large screen and a strong sound so as to beat sensory information in the real world [5]. In other words, this immersion is influenced by the technological system itself.

\section{B. Narrative Immersion}

Narrative immersion is an intense state and the attention of the audience is focused on the world of the story being created, so that, the story is made indirectly and the audience accepts it as real or actually happens. Narrative immersion can be caused by a strong sense of place and pleasure of exploration (spatial), by desire to know what will happen next (temporal), and 
brought about by the emotional bond with the character (emotional) [5].

\section{Challenge-based Immersion}

Challenge-based Immersion is an intense and focused attention on evaluating obstacles that occur and responding with appropriate actions. This immersion is influenced by a challenge that is usually found in games that have interactive elements. This challenge is deliberately made so that the user is more interested in trying further so that he also delves deeper [5].

\section{NRMO VIDEO MAPPING}

NRMO is the title of Lzy Visual's video mapping work at the 2018 Jogjakarta Video Mapping Festival, with a duration of three minutes and thirty one seconds presenting performing arts with impressive 2D \& 3D content as well as audio visuals combined with a narrative which tells a story of the reality of life to accept. The shooting media of NRMO video mapping is at the BNI Malioboro Yogyakarta building. Media is one of the important elements in video mapping. Mapping content that will be created by creators should adjust the media first. The media that becomes the object of shooting is the outer side of a building which is generally the front side. This becomes the limitation of the video mapping media (facade). The size of the media in the video mapping is of course converted into a pixel resolution size. In NRMO, the size that was previously more or less $40 \mathrm{~m} \times 15 \mathrm{~m}$, but then changed to $3400 \mathrm{px} \times 1280$. Here is the media of NRMO video mapping (figure 2).

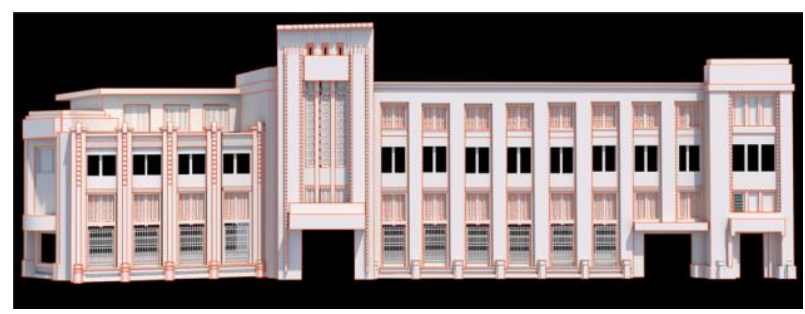

Fig. 2. Façade NRMO video mapping.

\section{A. Narrative structure on NRMO Video Mapping}

The NRMO narration is about a life story where everyone must accept what God has given them. There are people who are impatient when they start something which in the sense that it can be in work, love or otherwise, these people are mostly already feel that they have tried their best when doing something. Most of them are easily satisfied even though in reality they have actually not achieved anything compared to others. These people complain a lot in the process of achieving something because they feel that there is nothing to help them, even though, they have worked hard but in the end they still fail. In the end, they actually don't need to be disappointed or complained about what they have done with different results from what they wanted from the start because basically every process they have done has been set up and if facing problems, they need to accept it and look for solutions.

\begin{tabular}{|c|c|c|c|c|c|c|c|c|c|c|c|}
\hline \multicolumn{3}{|c|}{ SQUANCE/BABAK 1 } & \multicolumn{3}{c|}{ SQUANCE/BABAK 2 } & \multicolumn{3}{c|}{ SQUANCE/BABAK 3 } \\
\hline \multicolumn{2}{|c|}{ SCENE } & \multicolumn{2}{|c|}{ SCENE } & \multicolumn{2}{c|}{ SCENE } & \multicolumn{2}{c|}{ SCENE } & \multicolumn{2}{c|}{ SCENE } & \multicolumn{2}{c|}{ SCENE } \\
\hline shot & shot & shot & shot & shot & shot & shot & shot & shot & shot & shot & shot \\
\hline
\end{tabular}

Fig. 3. Sequence, scene, and shot.

The structure of this video mapping is similar to the structure in the film. The most popular of which is the three-act structure consisting of an opening, middle and ending (figure 3 ). Another language of the act is sequence. One sequence consists of several scenes which have the same setting/concept and a combination of several shots. In the video mapping, the displacement of each round or sequence is a fade in and a fade out or displays a visualization of bridging.

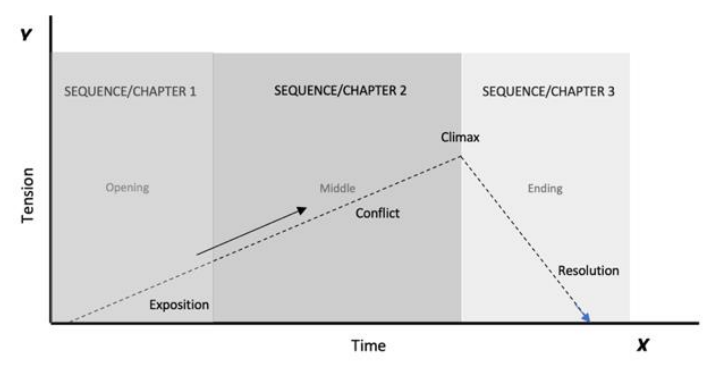

Fig. 4. Exposition, conflict, climax, resolution

The three-act structure is a very practical and effective structure to attract the audience (see figure 4). It is a script writing commonly used for animation, film, TV and drama or it is called the "Three-act structure" [14]. Therefore, video mapping has the same structure. The difference is how this story can be conveyed to the audience with video mapping techniques that play a lot of dominant visual elements for exposition. This conflict, climax, and resolution is felt even though it is not presented in detail like in the film.

\begin{tabular}{|l|l|l|l|l|}
\hline Sequence & Visualization & Visual Description & Technique & Duration \\
\hline I & $\begin{array}{l}\text { The sequnce shows } \\
\text { a man who is } \\
\text { touching and } \\
\text { opening curtain to } \\
\text { see what happens } \\
\text { outside. }\end{array}$ & $48 \mathrm{sec}$ \\
& $\begin{array}{l}\text { Interpretation: } \\
\text { Touching is one of the ways to reveal } \\
\text { something and the act of opening curtain } \\
\text { answer the curiosity of what happens } \\
\text { outside. }\end{array}$ \\
\cline { 2 - 5 } & Voice over: & & \\
\hline
\end{tabular}

Fig. 5. Chapter 1 opening / exposition video mapping NRMO.

This is a detailed structure of the three-act structure on NRMO video mapping: Chapter 1 (figure 5) is the opening of this video mapping without voice over using, but only sound effects, consisting of 4 scenes with 48 second duration. This chapter wants to provide an initial explanation of the opening of a story by showing a building object, hands opening the curtains to see the outside world. 


\begin{tabular}{|c|c|c|c|c|}
\hline Sequence & Visualization & Visual Description & Technique & Duration \\
\hline \multirow[t]{2}{*}{ II } & Witit. & $\begin{array}{l}\text { The sequence } \\
\text { shows the outside } \\
\text { condition such as } \\
\text { rain; people } \\
\text { chained, fall off, } \\
\text { get up, run from } \\
\text { something, tied, } \\
\text { etc; buildings } \\
\text { collapse; etc. }\end{array}$ & $3 \mathrm{D}$ & $132 \mathrm{sec}$ \\
\hline & $\begin{array}{l}\text { Voice over: } \\
\text { "No one tells this to } \\
\text { beginners when I just } \\
\text { started, I hope someone } \\
\text { tells me, I'm trying hard, } \\
\text { trying to be better, but } \\
\text { the results are on the } \\
\text { contrary, it makes me } \\
\text { disappointed". }\end{array}$ & \multicolumn{3}{|c|}{$\begin{array}{l}\text { Interpretation: } \\
\text { Rain is identic with the condition of sadness, } \\
\text { bounded, and entangled by something. } \\
\text { Fall off and get up are normal in life. } \\
\text { Run from something is not necessary as you } \\
\text { have yet to know what chase you. } \\
\text { Tied can be interpreted to motivational } \\
\text { action to get you back. } \\
\text { Buildings collapse are the symbol of people } \\
\text { who always face out-of-plan reality. }\end{array}$} \\
\hline
\end{tabular}

Fig. 6. Chapter 2 conflict, climax NRMO video mapping.

Chapter 2 (figure 6) has the longest duration with 2 minutes 12 seconds. Chapter 2 is the content of a story, starting with conflict and at the end of the climax which is packaged in 13 scenes, the sound effect is combined with a voice over which means "No one tells this to beginners when I just started, I hope someone tells me, I'm trying hard, to try to be better, but the results are on the contrary, it makes me disappointed". This part tells the audience how the state of the world, in human life who are born into the world always face problems. There are times of fall and wake up, there are always plans that fail, but don't worry there is always a way to deal with it.

\begin{tabular}{|l|l|l|l|l|}
\hline Sequence & Visualization & Visual Description & Technique & Duration \\
\hline III & $\begin{array}{l}\text { The sequence } \\
\text { shows a man sitting } \\
\text { and doing } \\
\text { introspection. }\end{array}$ & $3 \mathrm{D}$ & $26 \mathrm{sec}$ \\
& $\begin{array}{l}\text { Voice over: } \\
\text { I realize that just by } \\
\text { facing problems, we will } \\
\text { get closer to our } \\
\text { ambition, while if the } \\
\text { way to get there is } \\
\text { different, just take a } \\
\text { break to evaluate. }\end{array}$ & $\begin{array}{l}\text { Interpretation: } \\
\text { Introspection is one of the ways to thing, } \\
\text { evaluate, or plan something. } \\
\text { Sit is a way to take a break or cool down for } \\
\text { a while. }\end{array}$ \\
\hline
\end{tabular}

Fig. 7. Chapter 33 resolution / closing NRMO video mapping.

Chapter 3 (figure 7) is a conclusion with the shortest duration of 26 seconds. There are only two scenes of people standing and sitting, telling us that once an attempt is made to solve some difficult problem, we just need to accept it, be patient, we need to rest, think, evaluate, or plan to solve the problem.

\section{ANALYSIS}

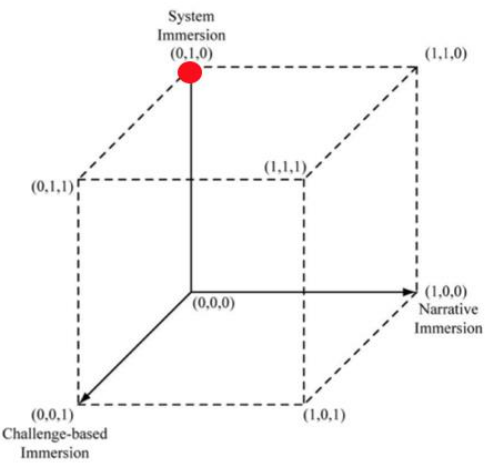

\begin{tabular}{|l|c|c|c|c|c|c|c|c|}
\hline \multirow{2}{*}{ Appreciator } & \multicolumn{7}{|c|}{ Corner } \\
\cline { 2 - 9 } & $(0,0,0)$ & $(0,0,1)$ & $(0,1,0)$ & $(0,1,1)$ & $(1,0,0)$ & $(1,0,1)$ & $(1,1,0)$ & $(1,1,1)$ \\
\hline Appreciator 1 & - & - & $\checkmark$ & - & - & - & - & - \\
\hline Appreciator 6 & - & - & $\checkmark$ & - & - & - & - & - \\
\hline
\end{tabular}

Fig. 8. Taxonomy appreciator 1 and 6 .

The taxonomy appreciator 1 and 6 (figure 8) is at point $0,1,0$ which means that this appreciator experiences a level of fun and focus with video mapping because of the technology presented. The appreciator does not feel cool and focus on following the story, especially the challenge factor that only exists in games with reciprocal interactions inside.

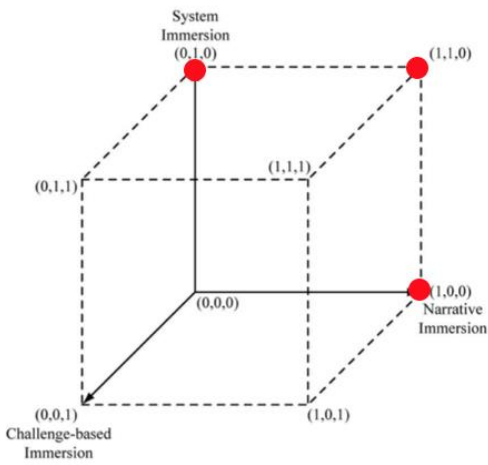

\begin{tabular}{|l|c|c|c|c|c|c|c|c|}
\hline \multirow{2}{*}{ Appreciator } & \multicolumn{9}{|c|}{ Corner } \\
\cline { 2 - 10 } & $(0,0,0)$ & $(0,0,1)$ & $(0,1,0)$ & $(0,1,1)$ & $(1,0,0)$ & $(1,0,1)$ & $(1,1,0)$ & $(1,1,1)$ \\
\hline Appreciator 2 & - & - & $\checkmark$ & - & $\checkmark$ & - & $\checkmark$ & - \\
\hline Appreciator 3 & - & - & $\checkmark$ & - & $\checkmark$ & - & $\checkmark$ & - \\
\hline Appreciator 4 & - & - & $\checkmark$ & - & $\checkmark$ & - & $\checkmark$ & - \\
\hline Appreciator 5 & - & - & $\checkmark$ & - & $\checkmark$ & - & $\checkmark$ & - \\
\hline
\end{tabular}

Fig. 9. A taxonomy appreciator 2, 3, 4, and 5.

Taxonomy Appreciator 2, 3, 4, and 5 (figure 9) have the same case at point $(0,1,0),(1,0,0)$, and $(1,1,0)$. This means that immersion in video mapping is due to technology factors and the narration because appreciators feel the technology and stories in the NRMO video mapping have a continuity with each other and cannot be separated from each other. Technology that produces visuals will be meaningless without a story in it, and vice versa. 


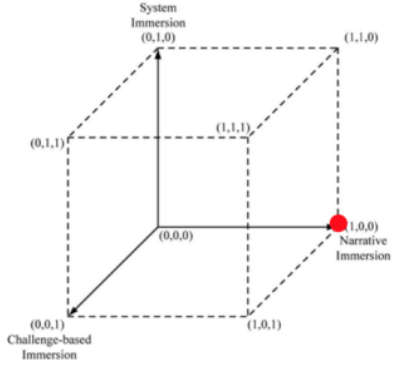

\begin{tabular}{|l|c|c|c|c|c|c|c|c|}
\hline \multirow{2}{*}{ Appreciator } & \multicolumn{9}{|c|}{ Corner } \\
\cline { 2 - 9 } & $(0,0,0)$ & $(0,0,1)$ & $(0,1,0)$ & $(0,1,1)$ & $(1,0,0)$ & $(1,0,1)$ & $(1,1,0)$ & $(1,1,1)$ \\
\hline Appreciator 7 & - & - & - & - & $\checkmark$ & - & - & - \\
\hline
\end{tabular}

Fig. 10. A taxonomy appreciator 7.

Taxonomy appreciator 7 (figure 10) has a different point from the others. Taxonomy appreciator 7 is at point 1.0,0 only. He felt more about the narration factor which made him enjoy the fun and focus on watching the NRMO video mapping.

\section{CONCLUSION}

NRMO Video Mapping by Lzy Visual in Jogjakarta Video Mapping Festival 2018 with a duration of 3 minutes 30 seconds is a narrative video mapping which has a story. Visual narrative structure contained in the NRMO video mapping is named a three-act structure which consists of opening, story content/climax, and a closing, so that the appreciator knows which parts are the beginning, the middle, and the end. The appreciator is able to know the narration. Even though displayed with a fairly short duration, the video mapping is still able to convey the message well. NRMO video mappimh telling stories about life, accepting, not giving up, taking breaks for introspection in facing problems can be enjoyed and understood by the audience. It could even produce immersion in video mapping that keeps the audience cool and focused in watching this NRMO video mapping.

There is an interesting discovery, for the appreciator or the audience presenting characters, displaying familiar objects such as clothes, hands, and rain. It will help the public to digest information appropriately and make people more interested. With a short duration, the video mapping is able to convey the message well, from the theoretical construct of video mapping having narrative, visual, audio, and projection elements. All of these elements are the main factors which emablig video mapping in producing immersion and narrative presentation with a three-act structure and visuals which display important things such as the existence of a story. Visual elements are constructed to tell a story of characters who play a role, a visual narrative that has a world of its own, and a visual narrative that is applied in the facade of video mapping media. Audio is dominated by sound effects and voice over which clearly helps to convey this video mapping message. Projection in video mapping is also an important thing which is able to make immersion due to the video projection technology in media that is large enough and provides amazing dynamic video.
From these explanations, NRMO Lzy's Visual Video Mapping in the 2018 Jogjakarta Video Mapping Festival has a narrative structure, visual, audio, and projection which becomes interrelated factors that produce immersion. Immersion on video mapping in Nillson's taxonomy of existing conceptualizations of immersion are immersion and narrative immersion systems because video mapping has technology that provides a display experience on a large screen and sound, so having high tracking makes appreciators feel excited, engrossed, and focused on watching the video mapping, as well as the narration presented which makes the appreciator cool, focused, and want to know more about the story even to the extent that the feelings conveyed are like advice in the story. It can be felt that it is like watching a story in the sense that it is mentally absorbed by the story, the world, and the character shown. The researchers would like to thank Institut Teknologi Bandung, especially the supervisory lecturers, Mr. Intan and Mr. Banung, Also to the ICADE committee Universitas Pendidikan Indonesia for all the assistance in creating and this research.

\section{REFERENCES}

[1] B. Ekim, "A Video Projection Mapping Conceptual Design an Application: Yekpare," The Turkish Online Journal of Design, Art and Communication, Todiac, 2011, p. 10-18

[2] D. Maniello, Augmented Reality In Public Space Basic techniques for video mapping. Italy : Le Penseur, 2014, p. 4-8.

[3] T. Vaughan, Multimedia: Making It Work. 8th Edition. New York: McGraw-Hill, 2011, p. 1.

[4] A.I. Saidi, Desain, Media, dan Kebudayaan, Bandung: Penerbit ITB, 2015, p. 44

[5] N.C. Nilsson, R. Nordahl, and S. Serafin, "Immersion revisited: a review of existing definitions of immersion and their relation to different theories of presence," Human Technology, vol. 12, no. 2, 2016

[6] Z.G. Djalle, The Making Of 3D Animation Movie using 3DStudioMax. Bandung: Informatika, 2006, p. 1.

[7] I. Binanto, Multimedia Digital Dasar Teori + pengembangannya Yogyakarta: C.V Andi Offset, 2010, p. 2-3.

[8] O.U. Effendy, Dimensi-Dimensi Komunikasi. Bandung: Rosda Karya. 1986, p. 239.

[9] D. McQuail, Teori Komunikasi Massa Suatu Pengantar. Jakarta: Erlangga, 1997. p. 110.

[10] R.I. Indriyanti, Narasi Visual Kematian dalam Ilustrasi Cerita Rakya Anak Indonesia.Bandung: Program Studi Magister Desain, Institute Teknologi Bandung, 2018.

[11] F.H. Langga, Narasi Visual Islami dalam Animasi "Nussa". Bandung Program Studi Magister Desain, Institute Teknologi Bandung, 2019, p. 21-27.

[12] Y.W. Hidayat, H. Rante, and K.H.A. Subhan, Implementasi Teknik Sound Effect Dan Voice Over Dalam Pembuatan Video Dokumenter Perlindungan Anak Di Kawasan Dolly. Surabaya: Prodi Multimedia Broadcasting, Jurusan Telekomunikasi. Politeknik Elektronika Negeri Surabaya, 2011

[13] W. Jonata, Ilusi Optis Dalam Dunia Seni dan Desain. Jakarta Barat: BINUS University, 2012, p. $647-657$.

[14] T.Y. Mou, Creative Story Design Method in Animation Production Pipeline. Tainan: National Pingtung University, 2015, p. 129 